\title{
PROTOTIPO DE MURO ECOLÓGICO NO ESTRUCTURAL ELABORADO CON PRODUCTOS PLÁSTICOS TEREFTALATO DE POLIETILENO (PET).
}

\section{PROTOTYPE OF A NON-STRUCTURAL ECO-FRIENDLY WALL ELABORATED WITH PLASTIC PRODUCTS, POLYETHYLENE TEREPTHALATE (PET).}

Hernán José Hernández Durán

Arquitecto

Investigador | Universidad de Oriente

hhernandez@univo.edu.sv

\section{Resumen}

La presente investigación contempla un análisis de dos problemáticas que posee El Salvador: el déficit de vivienda de la población de escasos recursos y la sobreproducción de botellas de plástico de tereftalato de polietileno. La investigación busca relación estas dos problemáticas con los Objetivos de Desarrollo Sostenible, los cuales son una iniciativa impulsada por Naciones Unidas para dar continuidad a la agenda de desarrollo tras los Objetivos de Desarrollo del Milenio, y los dos objetivos relacionados son colaborar con el país e la creación de ciudades y comunidades sostenibles construyendo un prototipo de muro ecológico. Esta investigación busca, además, contribuir a la construcción de futuras viviendas de tipo social, reutilizando las botellas de PET como principal materia prima el cual es un plástico elaborado con tereftalato de polietileno que es utilizado en envases de bebidas y textiles, capacitando a los pobladores de las diferentes zonas del país a través de instituciones gubernamentales y no gubernamentales, convirtiéndolos en comunidades constructoras capaces de planificar, gestionar y elaborar lo necesario para ser ejes de desarrollo local. Además, se busca la disminución de estos plásticos en los ecosistemas terrestres y marinos, pues muchas de las botellas de PET, al no recibir un tratamiento de reciclaje, son enterradas, quemadas y muchas veces llegan a quebradas, ríos y finalizan en el océano, afectando la vida de diferentes especies.

Palabras clave: Muro ecológico, eco bloque, construcciones sustentables, arquitectura verde, tereftalato de polietileno.

\section{Abstract}

The present study contemplates an analysis of two of the present problems in El Salvador: 
the housing deficit in low-income population and the overproduction of plastic bottles made with polyethylene terephthalate. The research pretends to relate these two problems with the Sustainable Development Goals, an initiative launched by the United Nations to continue with the development agenda after the Millennium Development Goals. The two related goals are to collaborate with the country in the creation of sustainable cities and communities building up a prototype of an eco-friendly wall. This study pretends to collaborate in the construction of future social housing, reusing PET plastic bottles as the main raw material, qualifying the people in the community to plan, manage and create the necessary structures for the local development.

Besides, the reduction of plastic in land and marine ecosystems is actively pursued, since many of these bottles are not treated in recycling facilities, ending up in rivers and the ocean, damaging ecosystems and species.

Keywords: Eco-friendly wall, eco-block, sustainable building, green architecture, polyethylene terephthalate.

\section{Introducción}

La investigación contempla un análisis a dos de las problemáticas que posee El Salvador: el déficit de viviendas para la población de escasos recursos y la sobreproducción de botellas de plástico.

El Salvador es un país que posee una extensión territorial de 21,000 kilómetros cuadrados, con una población de $6,000,000$ de habitantes, con un déficit habitacional que afecta a 8 de cada 10 salvadoreños (INCAE, 20I6). Un 35.2\% de las familias forman parte del porcentaje de Pobreza (PNUD, 20I5). El sector de vivienda de tipo social no da abasto, afectando a la población más vulnerable, el cual no posee casa propia o cuyas casas están construidas con materiales no adecuados, como cartón o laminas.

El presente estudio aborda, asimismo, la problemática medio ambiental, como la sobreproducción de botellas de plástico elaboradas con Tereftalato de Polietileno (PET). Éste es el material utilizado para la elaboración de recipientes para diferentes tipos de bebidas. El PET, por sí solo, no es contaminante, pero por la falta de políticas medio ambientales y de cultura de reciclaje hacen del PET una amenaza para el medio ambiente: en el país hay una sobreproducción de éstos, los que afectan los ecosistemas terrestres y marinos, se desechan sin control en vertederos de basura, quebradas y ríos, y llegan al océano, o son enterrados y quemados, afectando de esta manera el medio ambiente. 
Por otra parte, existe una seria necesidad de viviendas dignas y construidas con materiales que no afecten al medio ambiente y a sus usuarios. además, es necesario que la materia prima de éstas sea de alta duración y calidad. Lamentablemente, la mayoría de las familias de escasos recursos no posee estas condiciones, utilizando en su mayoría como material de construcción, láminas galvanizadas o bolsas de nylon con madera. Evidentemente, estos materiales no son la mejor opción por la inseguridad que brindan y por sus condiciones térmicas, que podría afectar negativamente a las familias que viven en ellas.

Las botellas de PET poseen un tiempo de degradación de 700 años, y esta cualidad especial lo convierte en un excelente material alternativo de construcción. Su reutilización disminuiría la contaminación por plásticos, utilizando las botellas rellenas con tierra o arena para crear eco ladrillos, los cuales poseen las mismas características del adobe y una resistencia similar o mayor a de los ladrillos de obra y bloques de concreto, y por ser completamente reciclados, reducen los costos de construcción.

Para estudiar y evaluar este método constructivo con botellas se realizó un prototipo de muro ecológico no estructural, elaborado con productos plásticos de tereftalato de polietileno, similar a la construcción de paredes de ladrillo de obra. Ésta es una construcción con marcos reforzados y botellas confinadas. Se realizaron pruebas de peso y compresión a las botellas utilizando diferentes materiales. Este prototipo posee una dimensión de $1.5 \mathrm{~m}$ de largo y $3 \mathrm{~m}$ de alto, y fue construido en la Ciudad Universitaria de la UNIVO, ubicada en la Carretera Panamericana CA-I Kilómetro 133 1⁄2 Salida a San Salvador, San José, Quelepa, departamento de San Miguel, El Salvador. La Facultad de Ingeniería y Arquitectura posee en esas instalaciones un área destinada a proyectos, y cuenta con el laboratorio para realizar pruebas a los materiales utilizados.

La información que se tomó en cuenta para la realización de esta investigación fue recabada de los estudios acerca del tema en desarrollo, desde el enfoque de la Arquitectura Verde, un enfoque de la construcción también conocido como diseño sostenible. La arquitectura verde es un método de diseño que minimiza el impacto de la construcción sobre el medio ambiente (Taracena, 2010). Asimismo, se tomaron en cuenta experiencias en países de diferentes latitudes que han implementado este sistema constructivo y sistemas similares orientados al reciclaje de botellas de PET.

\section{Los objetivos de la investigación.}

\section{General.}

Desarrollar un muro ecológico no estructural elaborado con productos plásticos de 
tereftalato de polietileno (PET) que funcione como prototipo para futuras construcciones de viviendas.

\section{Específicos.}

"Elaborar un diseño de fundaciones y columnas para construir el prototipo.

"Construir un prototipo de un muro de mampostería confinada con botellas de PET. „Evaluar el comportamiento del muro aplicando esfuerzos de tensión y compresión.

Con esto se pretende lograr futuras construcciones sustentables en el país, que ayuden a las poblaciones de escasos recursos, y que proteja, asimismo, al medio ambiente reduciendo la contaminación de plástico y los costos de construcción, sustituyendo los ladrillos de obra o los bloques de concreto por botellas de plástico rellenas de tierra.

\section{Materiales y método}

El tipo de investigación es aplicada, porque se realizó esta basado en una mezcla de modelos científicos los cuales se complementaron uno con otro, Pues se posee de tipo descriptivo, documental en la recopilación de la información y aplicada en la construcción del prototipo.

El modelo descriptivo: El modelo descriptivo está basado en datos numéricos, medibles y estadísticos, en las propiedades físicas y en la resistencia de los materiales. Se obtuvo información por la experimentación, en este caso, se pusieron a prueba las botellas de PET y la propuesta del sistema constructivo.

\section{La investigación documental:}

Se detectó, obtuvo y consultó la bibliografía y se consultaron otros materiales relativos al tema, de manera selectiva, de modo que puedan ser útiles para el propósito de estudio (Hernández Sampieri , Fernandez, \& Baptista, 2000).

La investigación aplicada: Guarda relación con la investigación teórica, pues depende de los descubrimientos y avances de la investigación básica y se enriquece con ellos. Se trata de investigaciones encaminadas a la resolución de problemas, que se caracterizan por su interés en la aplicación y utilización de los conocimientos (Ander, 20I I).

\section{Diseño de Investigación e Innovación Tecnológica}

La investigación tecnológica en las ciencias de la ingeniería presenta una serie de características que la vinculan en forma natural con la innovación tecnológica, lo cual indica 
que las instancias de promoción inicial de los proyectos de investigación y la evaluación de la investigación tecnológica pueden ser utilizadas como un instrumento para fomentar la innovación. A continuación, se detallan los diferentes materiales utilizados para el desarrollo del prototipo de muro ecológico.

La selección de estos materiales está orientada según los métodos de construcción tradicionales, reemplazando el bloque de cemento y/o el ladrillo de obra por botellas plásticas, haciendo un sistema de botellas confinadas, sin la necesidad de utilizar acero de refuerzo vertical a cada $0.60 \mathrm{~m}$ como es el caso de las viviendas construidas con bloques.

Tabla I. Materiales utilizados en el Prototipo de muro ecológico no estructural elaborado con productos plásticos tereftalato de polietileno (PET)

\begin{tabular}{|l|c|c|c|}
\hline Materiales & Cantidad & Materiales & Cantidad \\
\hline Bolsas de cemento & 7 & Botellas de PET & 336 \\
\hline Decoblock & $\mathrm{I}$ & Nylon & 10 \\
\hline Arena & $0.5 \mathrm{~m} 3$ & Madera & $5 \mathrm{vra}$ \\
\hline Grava & $0.5 \mathrm{~m} 3$ & Clavos & 12 \\
\hline Agua & & Alambre de amarre & I rollo \\
\hline Hierro de 3/8 & 5 & Bloques I5x20x40 & 34 \\
\hline Hierro liso de I/4 & 6 & Tierra blanca & Im3 \\
\hline Hierro de I/2 & 3 & Tierra para rellenar & \\
\hline
\end{tabular}

Fuente: Elaboración propia

\section{Especificación de requisitos.}

\section{Descripción general.}

El propósito de este prototipo es analizar y documentar el correcto proceso de construcción de esta nueva metodología para la construcción de viviendas ecológicas.

\section{Perspectiva del producto}

Elaborar un muro ecológico con botellas plásticas para ayudar al medio ambiente reutilizando este tipo de material, que tarda entre 500 y 700 años en degradarse. Asimismo, se ayudará a solucionar la problemática de viviendas de interés social en El Salvador. Se elaborará un manual para poder replicarlo en cualquier zona del país en la que quisiera implementarse, capacitando a los pobladores de los lugares que requieran de la necesidad de vivienda, y dándoles las herramientas necesarias para que puedan construir sus viviendas. 


\section{Funcionalidad del producto.}

Las viviendas construidas con esta metodología de muros de botellas tendrán las ventajas que ofrece este sistema como se explica a continuación.

En vista que es un material altamente resistente ofrece durabilidad en sus paredes.

„Ayuda a disminuir la contaminación de plásticos PET, al reutilizar estas botellas para la construcción de viviendas.

"Reduce los costos de construcción, puesto que el costo unitario de un bloque de concreto de I 5x20x40 es de \$0.64 en San Miguel, \$0.53 en San Salvador, \$0.56 en Santa Ana y \$0.58 en Sonsonate. Esto puede variar a un precio mayor dependiendo de las dificultades de acceso de la zona. Estos costos unitarios pueden disminuir un poco según la cantidad de bloques negociados, pero al ser la construcción de estas paredes con botellas reutilizadas, no se gastará en la compra de bloques. Deberán realizarse campañas de recolección, las cuales pueden estar apoyadas por Organizaciones sin Fines de Lucro, Alcaldías o algunas Instituciones gubernamentales y no gubernamentales.

„Al ser una botella rellena de tierra, se convierte en un buen aislante térmico, que absorbe el calor durante el día y mantiene un clima fresco dentro de la vivienda; y por las noches, cuando el clima del interior de la casa es muy frio, libera el calor que absorbió durante el día climatizando el ambiente dentro de ella.

\section{Restricciones}

A continuación, se mencionan algunas restricciones impuestas para la implementación de este sistema de muros ecológicos:

"Las paredes utilizadas no serán de tipo estructural, ya que no están diseñadas para soportar cargas directas. Es necesario la implementación de un sistema de marcos reforzados para que éstos sean los que soporten cargas vivas y muertas.

"Las botellas se pueden rellenar con plásticos, bolsas, tierra o arena, pero no con material orgánico que pueda degradarse, ya que puede generar gases, los cuales al estar encerrados podría causar fallas en el muro.

\section{Requisitos específicos.}

\section{Requisitos funcionales.}

„Para la construcción de este tipo de muros se puede utilizar cualquier tamaño de botellas de PET, aunque se recomienda de su tamaño menor sea de I litro. En el caso de este prototipo, se trata de envases de soda de 1.25 litros. Cuanto mayor sea el tamaño de las botellas, más gruesas serán las paredes, pero se necesitarán menos botellas; mientras más pequeñas sean las botellas, más delgadas serán las paredes, y se necesitará recolectar la mayor cantidad de 
botellas.

"Las botellas se pueden rellenar con plásticos o bolsas. Esto ayudará a que la vivienda sea aún más ecológica. Estas bolsas y plásticos tendrán que estar compactados dentro de la botella. "Las botellas se pueden rellenar con tierra o arena, que pueden provenir del mismo lugar de la construcción.

\section{Mantenibilidad}

"Como cualquier casa construida con un sistema tradicional, es necesario brindarle mantenimiento a las paredes; se recomienda no golpearlas con martillo y clavos.

"No destapar las botellas, puesto que se puede salir el material con el que fue rellenado.

\section{Diseño del prototipo}

\section{Introducción: diseño del prototipo}

En esta sección que se muestra el diseño del muro ecológico y su desarrollo.

Se muestra un modelo conceptual que servirá como una aproximación de la forma y a su vez como una guía de cómo se estará el muro al finalizar el proyecto, a continuación:

\section{Figura I: Materiales para la construcción del ecoladrillo.}

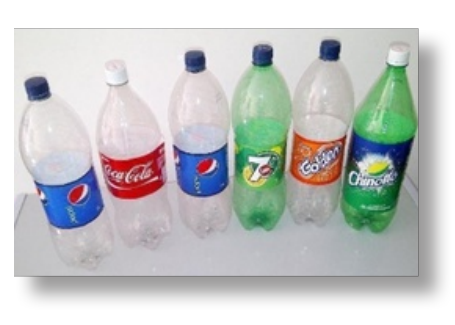

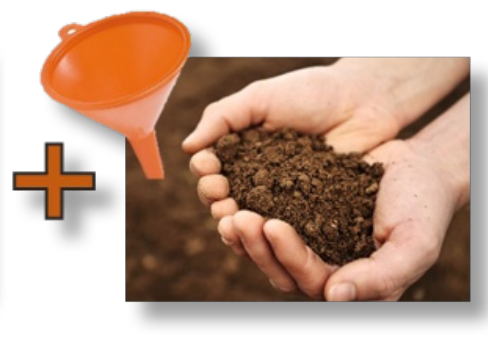

Fuente: Elaboración propia

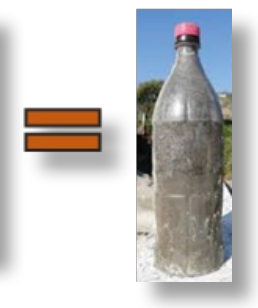

El principal material para la construcción del muro son botellas de plástico, las cuales se rellenarán con tierra del lugar de donde se construirá. Se pueden utilizar otros tipos de materiales para rellenar estas botellas, como plásticos o bolsas, aunque se recomienda no utilizar materiales orgánicos puesto que éstos se descomponen y podrían generar gases que afecten la construcción. 
Figura 2: Detalle de solera de fundación.
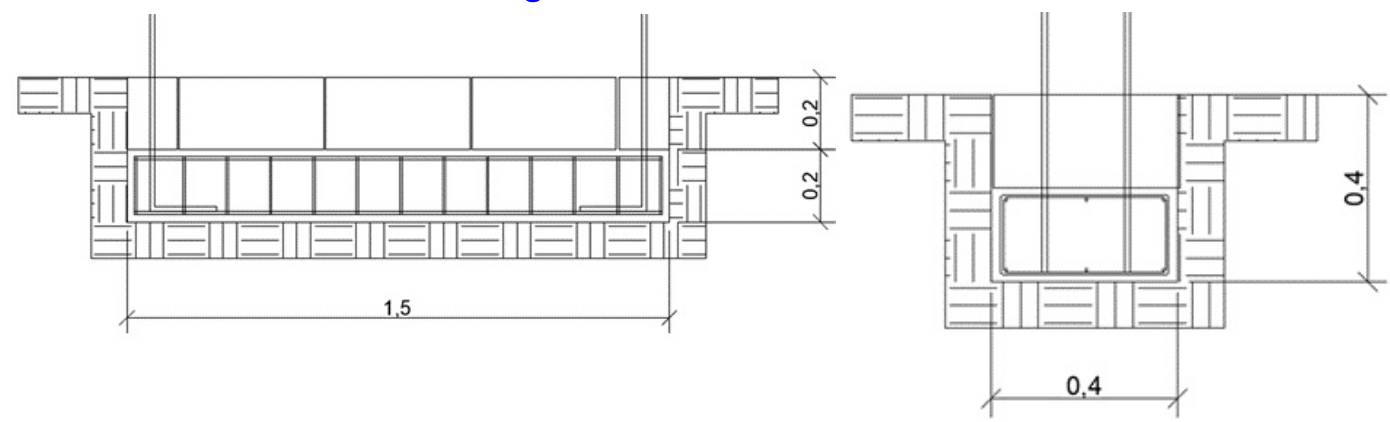

Fuente: Elaboración propia

Cuenta con una excavación de 0.40 × 0.40 m., la solera tendrá acero longitudinal de 3/8" con estribos a cada $0.15 \mathrm{~m}$ de $1 / 4^{\prime \prime}$ y refuerzo vertical de 2 varillas de $1 / 2^{\prime \prime}$ a sus extremos; se utilizó una dosificación del concreto de 1:2:2.

Figura 3: Detalle de pared de botellas de PET, vista frontal y lateral.

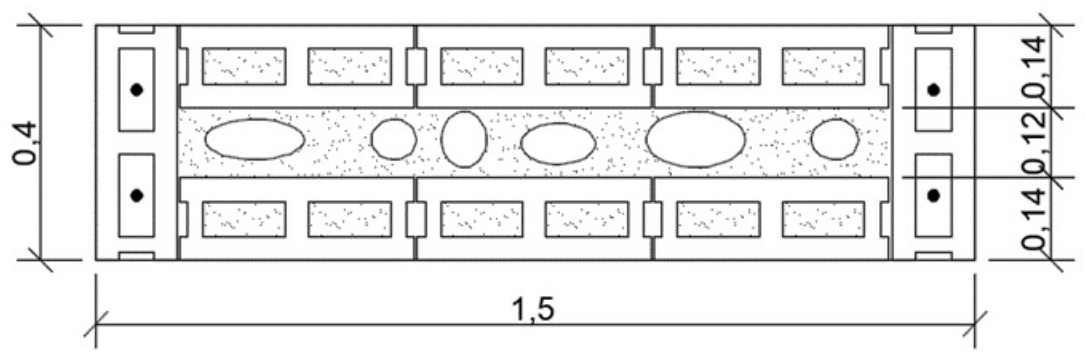

Fuente: Elaboración propia

Su función es nivelar el terreno donde se colocarán las botellas y dar estabilidad. Es $s$ necesario la nivelación del terreno donde se construirán las paredes, para que la pared quede nivelada.

Figura 4: Detalle de pared de botellas de PET, vista frontal y lateral.

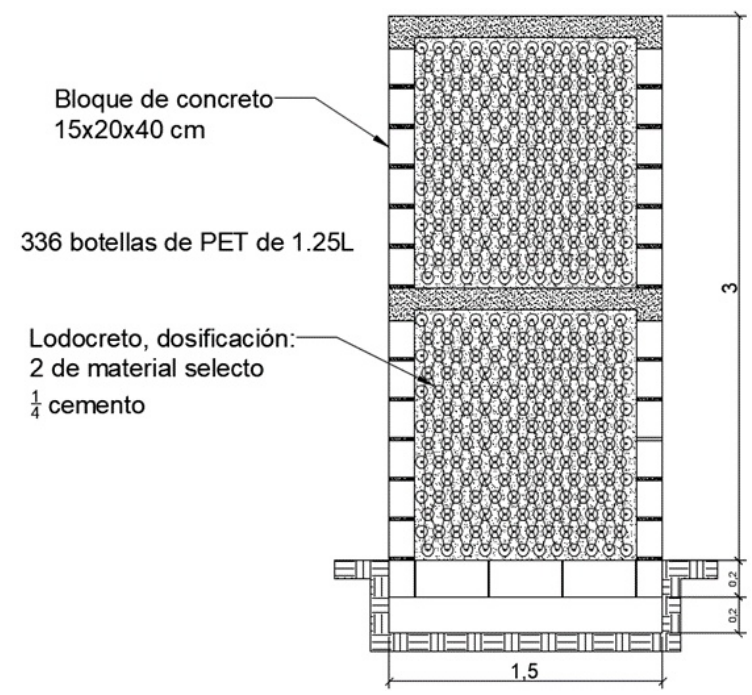

Fuente: Elaboración propia 
Figura 5: Esquema de construcción del muro ecológico.

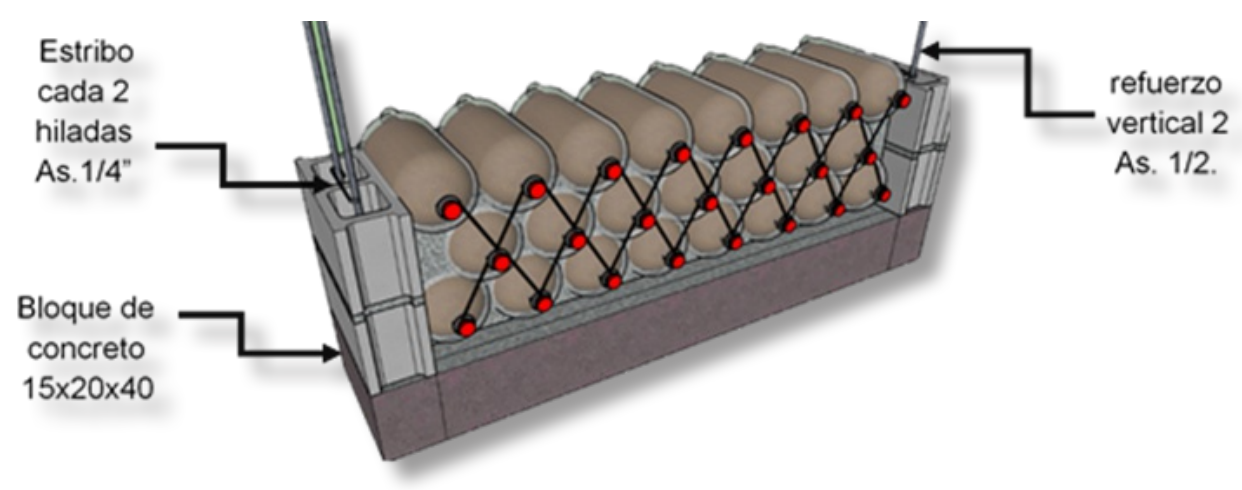

Fuente: Elaboración propia

Para esto se utiliza un sistema mixto. Una construcción tradicional, que soportará la carga viva y muerta, y estará comprendida por solera de fundación, columnas y soleras intermedias o de coronamiento. Y, en sustitución de bloques de concreto o de ladrillo de obra, se utilizarán botellas de PET, amarradas con nylon entrelazándolas para crear una estructura tipo red, la cual dará estabilidad y refuerzo.

\section{Especificaciones}

Para realizar este tipo de edificaciones, es necesario recolectar las botellas, que será el material que sustituirá los elementos de construcción tradicionales, como los bloques de concreto y los ladrillos de barro cocido. Teniendo esto se elige la metodología de construcción con las botellas; si se utilizarán como eco ladrillos, como sistema confinado de PET, en nuestro caso se utilizarán eco ladrillos, que consiste en rellenar las botellas plásticas con tierra, arena, o materiales plásticos y objetos no orgánicos.

Se prepara el terreno de construcción, realizando limpieza en la zona de construcción, comenzando con el trazo y la nivelación del terreno. Posteriormente se realizan las excavaciones para las fundaciones de las paredes y columnas.

Se hace la armaduría de la solera de fundación y columnas, y se realiza el colado del concreto de la solera de fundación, dejando sin colar las columnas.

Se realiza la nivelación con pita o nylon para las hiladas de las botellas, las cuales irán pegadas con mortero o con una mezcla de tierra blanca y cemento. Las botellas irán amarradas entre sí, en forma de red, entrelazándose y haciendo que las botellas trabajen como un solo elemento. De igual manera éstas irán amarradas en el acero vertical de las columnas, para posteriormente realizar el colado de éstas. Otra forma que se puede realizar es la sustitución de las columnas por bloques rellenos de concreto armado para darle mayor 
resistencia a los esfuerzos de tensión.

Es recomendable la utilización de solera intermedia y solera de coronamiento para darle mayor resistencia y solidez a la pared. Las distancias entre las columnas de apoyo son de 3 a $4 \mathrm{~m}$. de separación, pero al utilizar paredes circulares no afecta la omisión de las columnas Estas paredes al ser rellenas con tierra adquieren las características del adobe, pero la cubierta plástica le brinda mayor protección al material.

\section{Pruebas de laboratorio}

Figura 6: Realización de pruebas a las botellas. (Fuente: elaboración propia).
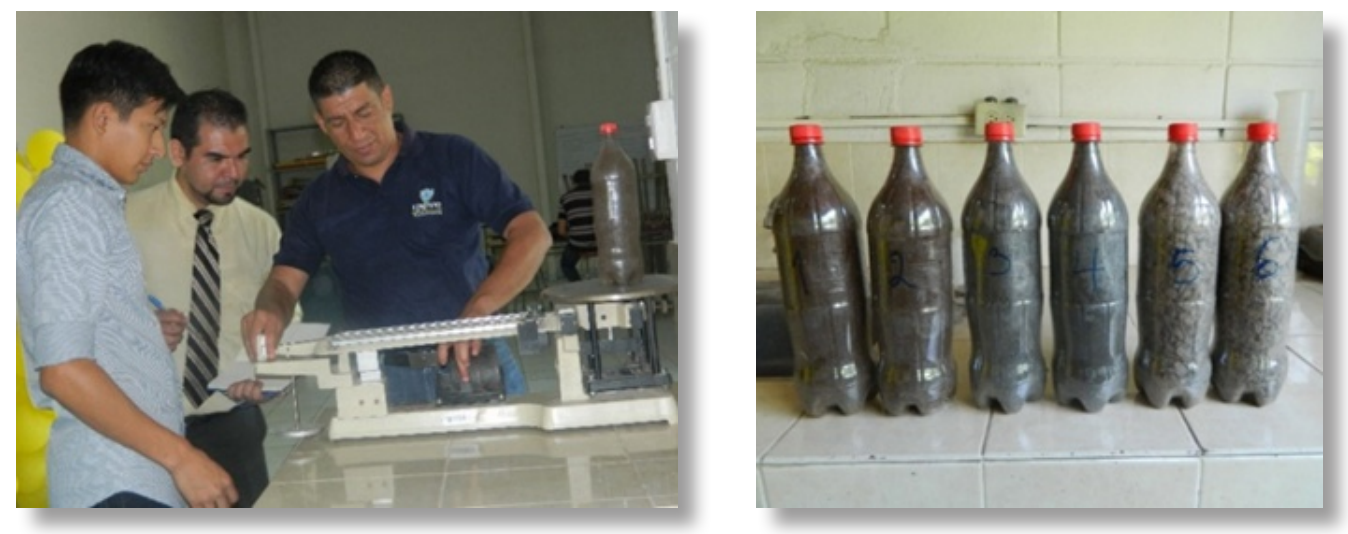

Fuente: Elaboración propia

Se enumeró del I al 6. Botella I y 2 rellenas de tierra, 3 y 4 rellenas de arena, 5 y 6 rellenas de grava. Se pesó cada una de ellas.

Figura 7: Se realizaron las pruebas de compresión de las botellas, ajustando la maquinaria de compresión para que la carga aplicada, fuese distribuida. (Fuente: elaboración propia).
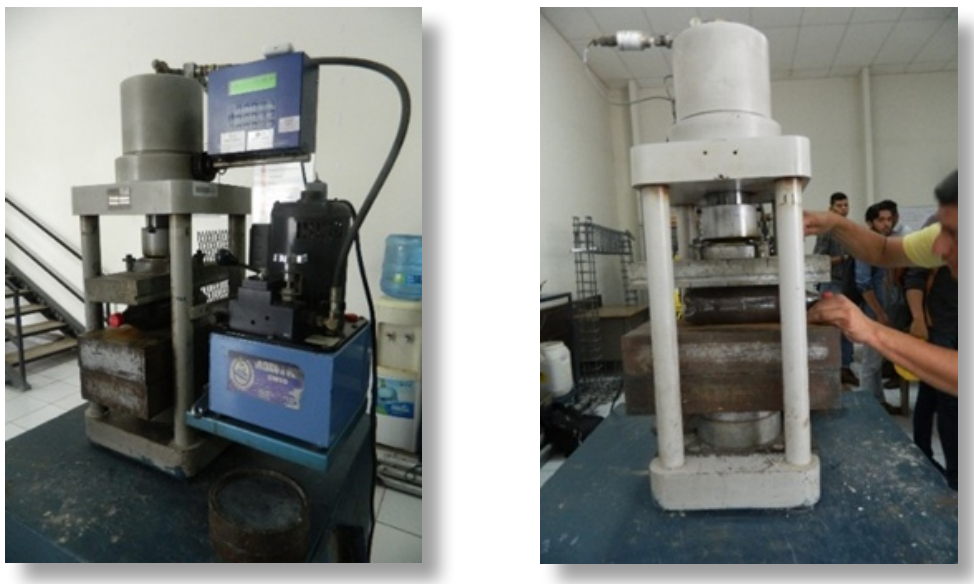

Fuente: Elaboración propia 
Figura 8: Registro de resultados obtenidos con la prueba de compresión. (Fuente: elaboración propia).
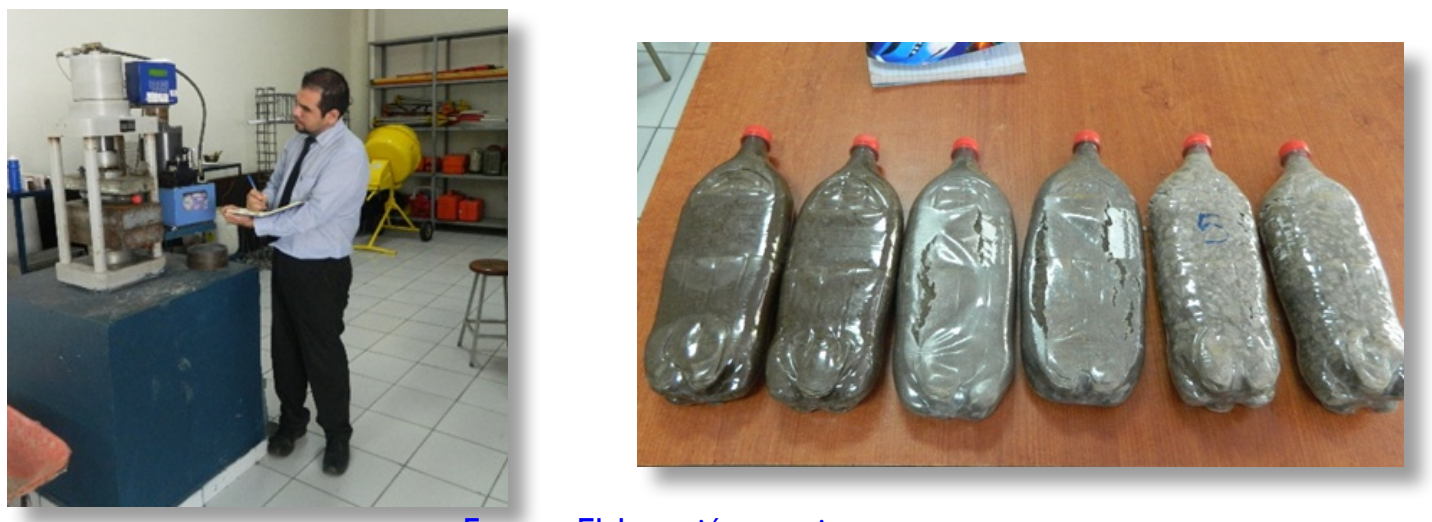

Fuente: Elaboración propia

Gráfico I: Resistencia de botellas según los materiales utilizados de rellenos.

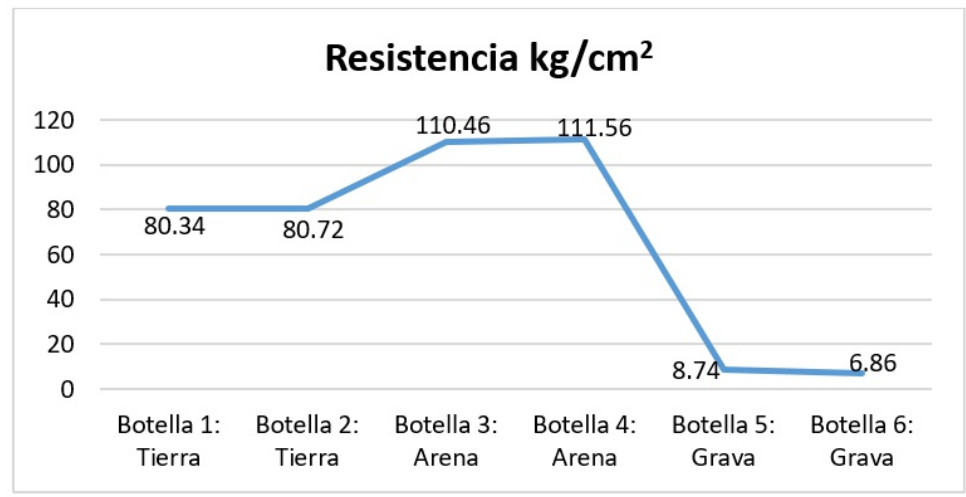

Fuente: Elaboración propia

Teniendo estos resultados se observa que los mejores materiales de rellenos para la botella de PET son la arena y la tierra. Al aplicarle mayor compresión la botella no falla, rompiéndose al sobrepasar los $80,000 \mathrm{~kg}$. de presión aproximadamente. El peor material de relleno es la grava, puesto que por ser un material de tipo granular, hace que al someterlo a presión se rompa más rápido, con tan solo los $4,988 \mathrm{~kg}$.

Gráfico 2: Peso de las botellas según el material de relleno utilizado.

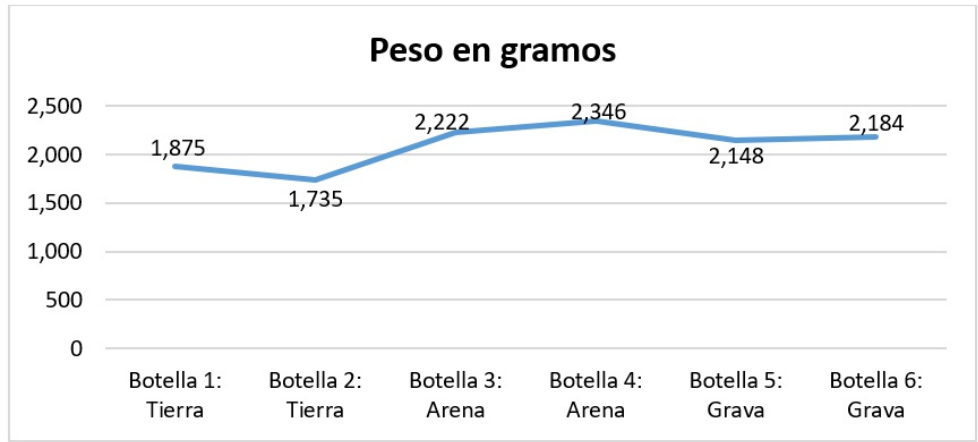

Fuente: Elaboración propia 
Haciendo la relación de resistencia y peso, las botellas que fueron rellenas de tierra fueron las más livianas y a su vez presentaron un alto grado de resistencia a la compresión, al contrario de las botellas rellenas de grava, las cuales fueron las más pesadas y su resistencia fue inferior a los otros rellenos implementados.

\section{Construcción del Prototipo de muro ecológico no estructural elaborado con productos plásticos tereftalato de polietileno (PET)}

Figura 9: El principal paso para la construcción del prototipo fue la recolección de botellas de soda de 1.25 Litros, para esto se contó con la colaboración de docentes y estudiantes de la Facultad de Ingeniería y Arquitectura. Con esto se logró que las botellas se reutilizaran para la construcción del prototipo y no fueran desechadas sin un tratamiento adecuado.
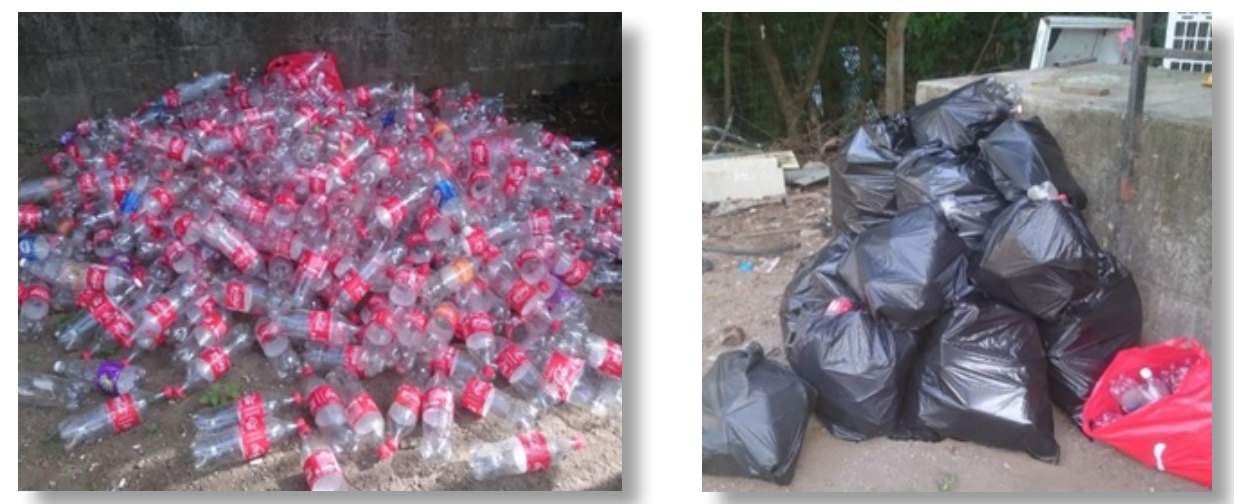

Fuente: Elaboración propia

Figura 10: Se consiguió tierra para rellenar las botellas plásticas de I.25 litros. En la construcción de una vivienda con este sistema se recomienda la utilización de la tierra de las excavaciones de las fundaciones y descapote.
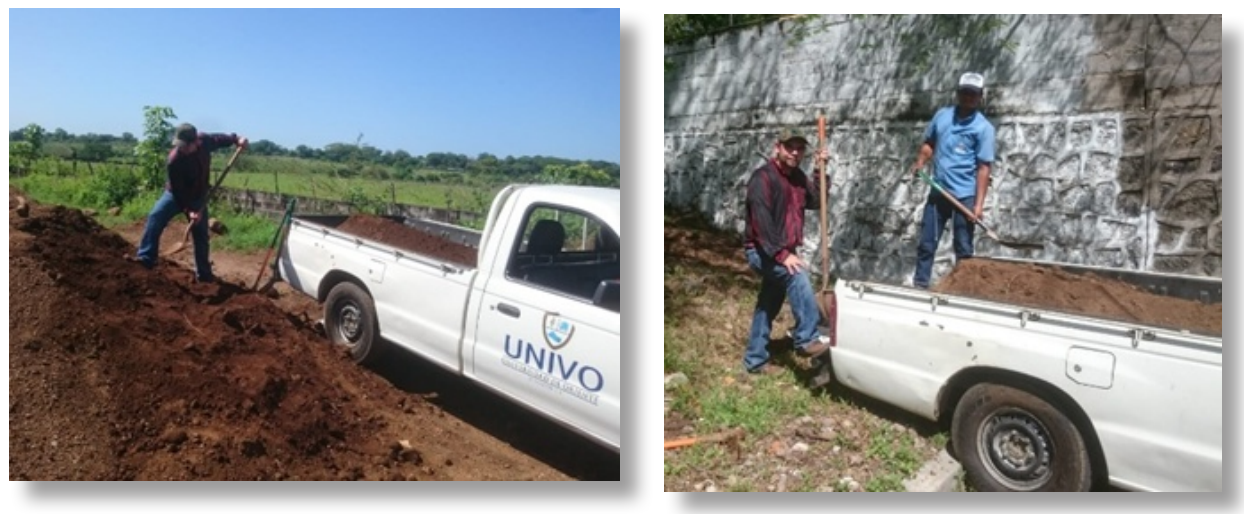

Fuente: Elaboración propia 
Figura I I: Estudiantes de Ingeniería civil de la cátedra de Métodos y técnicas de investigación colaborando con el llenando las botellas de PET de I.25 I.
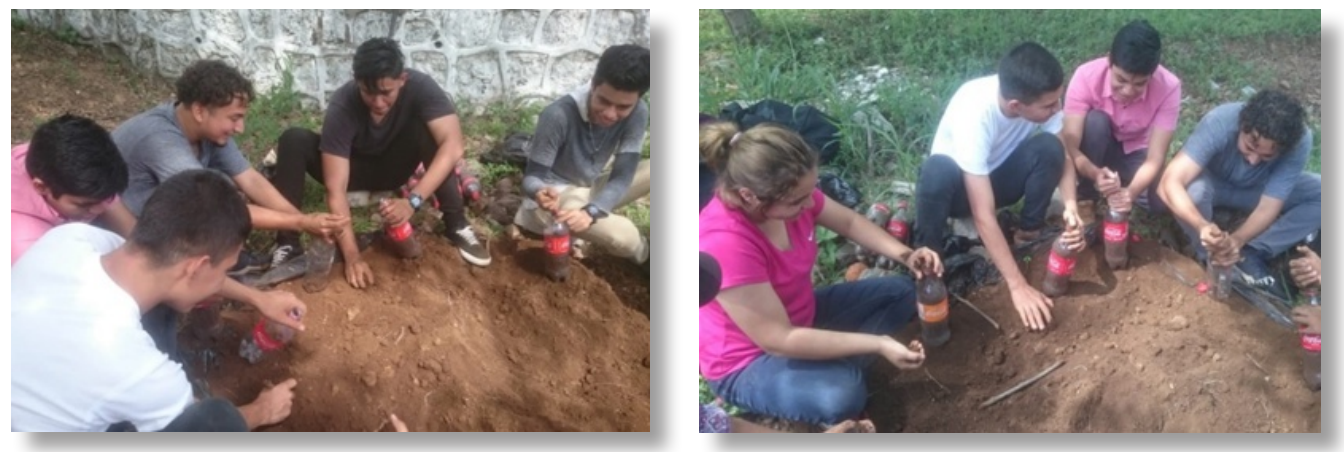

Fuente: Elaboración propia

Figura I2: Excavación y armaduría para solera de fundación.
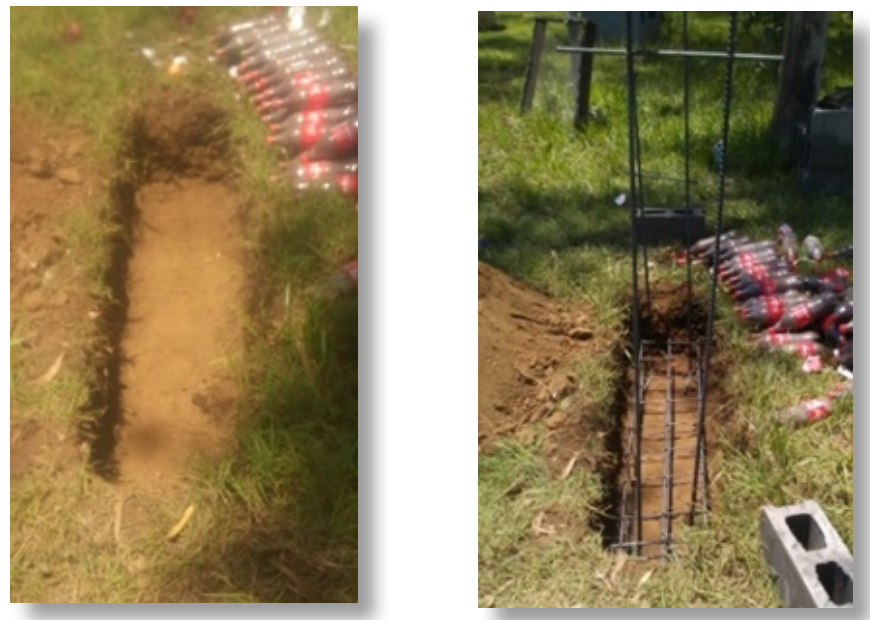

Fuente: Elaboración propia

Figura 13: Base de la pared; tiene la función de nivelar el terreno donde se colocarán las botellas.
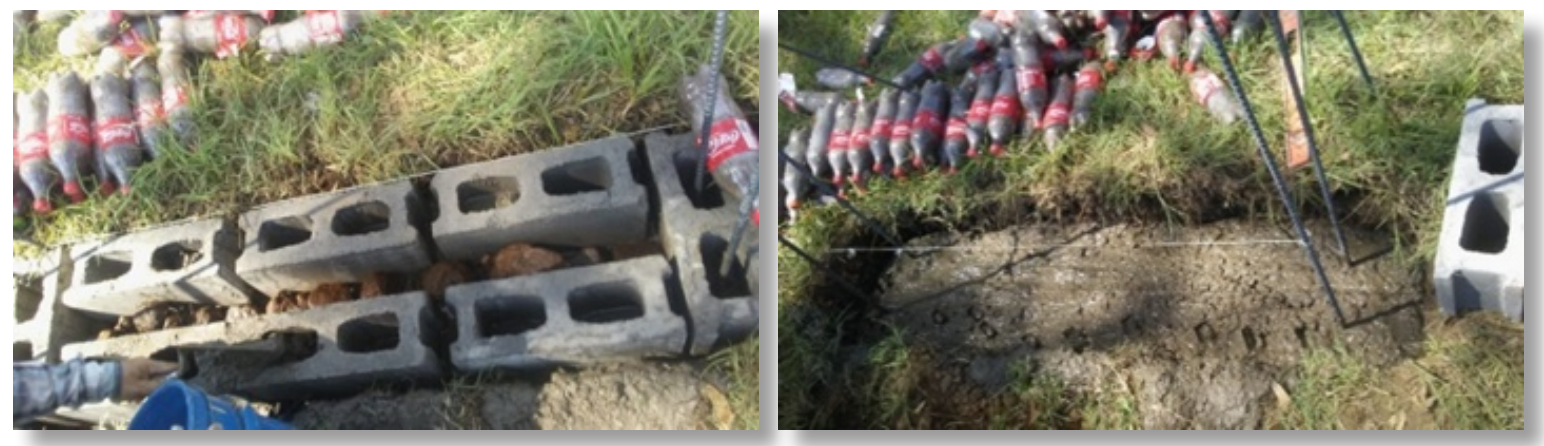

Fuente: Elaboración propia 
Figura 14: Modulación y colocación de las botellas, amarradas entre ellas y pegada con una mezcla de 2 carretilladas de material selecto y I/4 de la bolsa de cemento, se colocan los estribos a cado 2 hiladas de bloques.
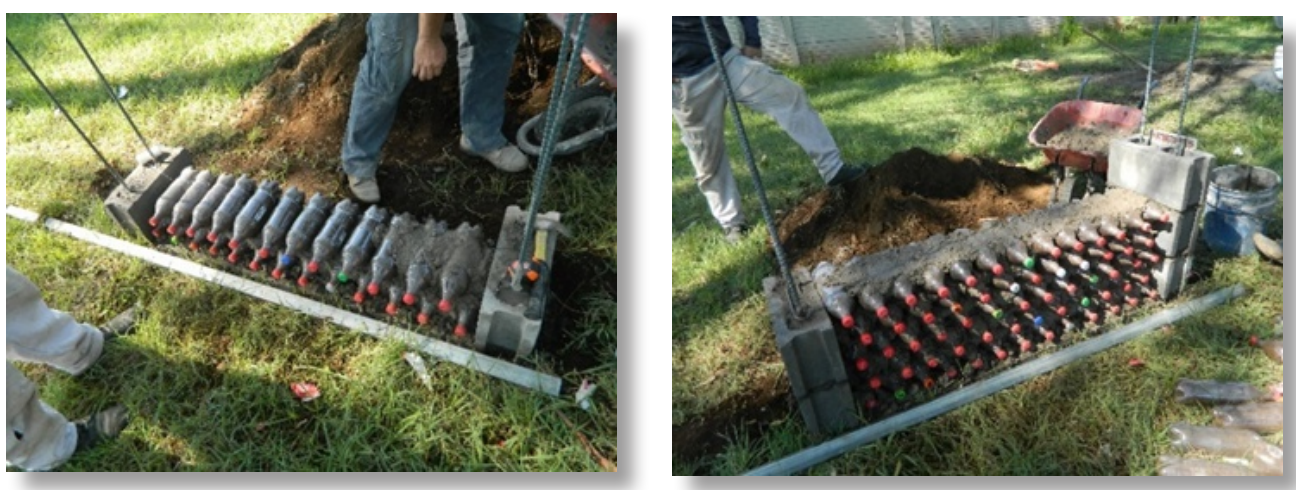

Fuente: Elaboración propia

Figura 15: Colocación y colado de la solera intermedia acero Longitudinal 4 Varillas de 3/8 y estribos de I/4 @ $15 \mathrm{~cm}$.
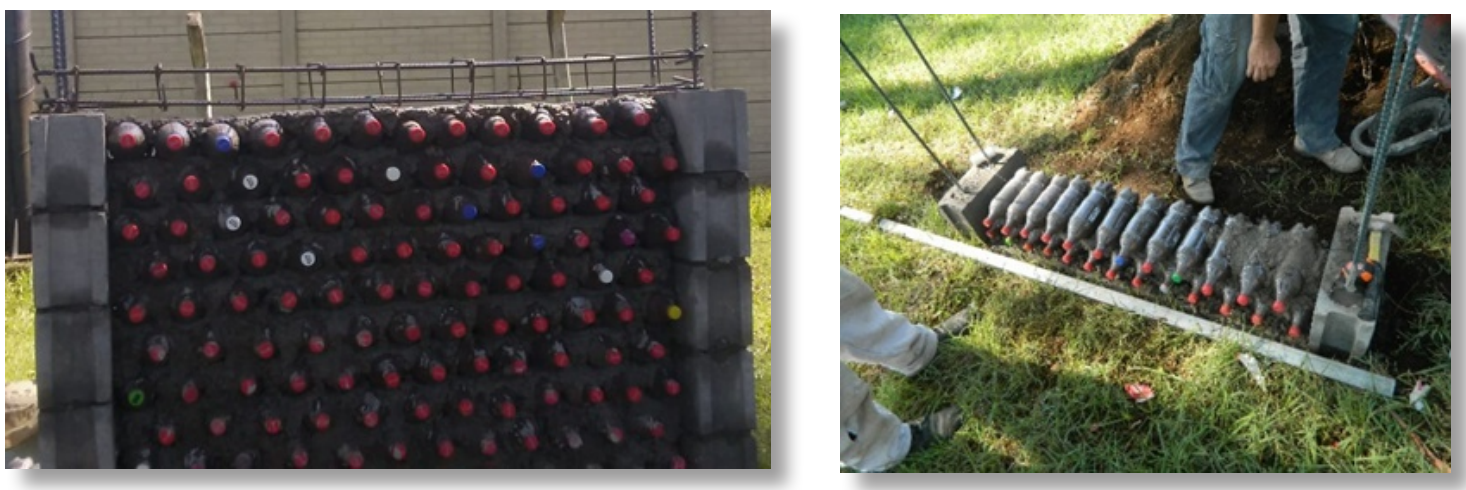

Fuente: Elaboración propia

Figura 16: Colocación y colado de la solera de coronamiento As. Longitudinal 4 varillas de 3/8 y estribos de I/4 @15cm.
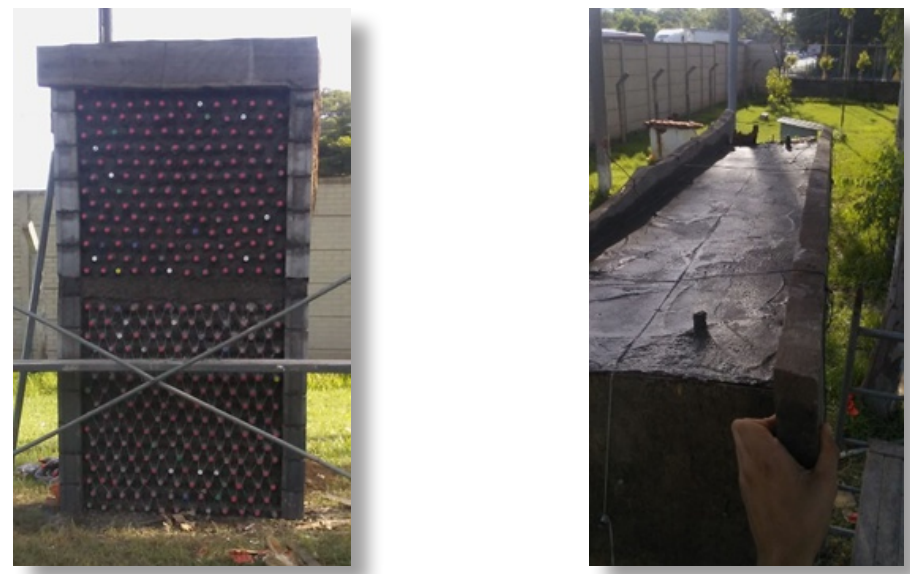

Fuente: Elaboración propia 
Figura 17: Muro de botellas plásticas repellado y afinado.

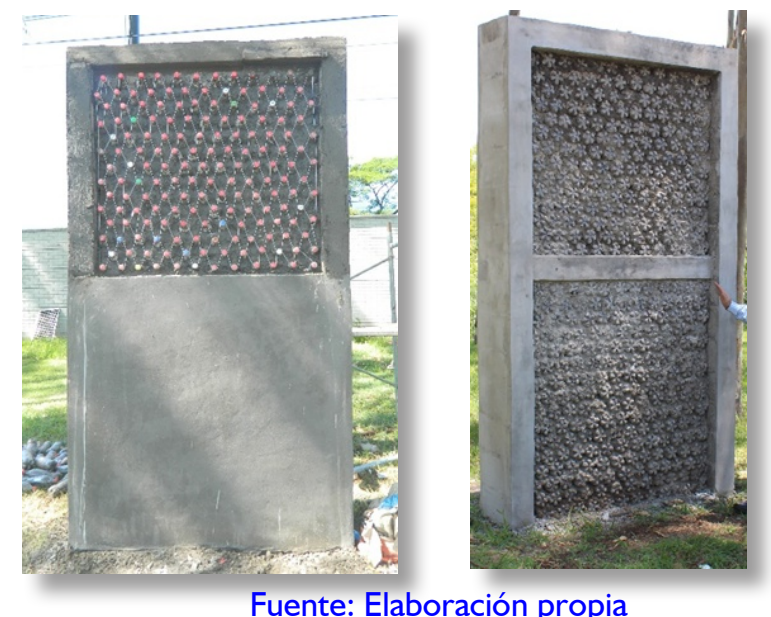

\section{Discusión.}

La investigación consistió en el diseño y construcción del "Prototipo de muro ecológico no estructural elaborado con productos plásticos de tereftalato de polietileno (PET)", que tuvo como objetivos: Identificar las alternativas existentes de sistemas constructivos con base en residuos sólidos reciclados; elaborar un diseño de fundaciones y columnas para construir el prototipo; construir un prototipo de un muro de mampostería confinada con botellas de PET, y evaluar el comportamiento del muro aplicando esfuerzos de tensión y compresión. Asimismo, sus resultados estuvieron orientados mediante las cuestiones: iSe reducirán los costos en la construcción y se ofrecerá nuevas alternativas de viviendas dignas y en armonía con el medio ambiente?

Bajo ese sentido los resultados dependen del diseño y modelo de investigación: el modelo es de tipo aplicativo y el diseño de investigación e innovación tecnológica, apropiada al desafío de medio ambiente y al desafío de construcción en El Salvador. De este modo, se plantea una discusión teórica, investigativa y de análisis. El problema de investigación y su planteamiento metodológico estuvieron enfocados hacia el logro de los objetivos a la Agenda 2030, y a los objetivos de desarrollo sostenible. Los resultados de investigación se plantean en base al logro de los objetivos:

a. La identificación de las alternativas existentes de sistemas constructivos con base en residuos sólidos reciclados.

Que el mundo ha cambiado en materia del medio ambiente y en materia de ingeniería de la construcción. Es importante destacar que El Salvador cada vez presenta mayores niveles de pobreza y accesibilidad a la vivienda. En esta investigación fue relevante destacar esto, así 
como. Sus resultados indican que existen diferentes materiales alternativos para los sistemas constructivos, y en este caso, el objeto de investigación conllevó a la identificación de unos de los componentes de la economía circular: el material reciclable plástico para caso de la investigación se trabajó con PET (Tereftalato de Polietileno): un polímero derivado del petróleo, liviano y de gran resistencia, utilizado en diferentes tipos de plásticos en la industrias de las bebidas en El Salvador.

Para el caso de la investigación se realizó una campaña que consistió en la recolección de botellas plásticas de I.25 I. de soda. Para el experimento se recolectaron I,500 botellas y de estas se realizó una identificación técnica de 336 las cuales tenían que cumplir con los siguientes requisitos: que cumplieran con la medida requerida, que se encontraran en buen estado, que estuvieran limpias y que contaran con tapadera. Se rellenaron con tierra, la que se comprimía dentro de la botella para brindarle mayor dureza y resistencia. Luego de ser rellenas se realizaron pruebas de laboratorio, y para eso se realizaron pruebas con tres diferentes materiales: dos botellas con tierra, dos botellas con arena y dos con grava. Se pesaron las botellas en báscula de precisión; las que pesaron menos fueron las botellas de tierra, seguidas por las de arena y finalizando con las rellenas de grava. Posteriormente se realizaron pruebas de resistencia a la compresión. Los resultados indican que tuvieron mejor resistencia a la compresión las botellas rellenas de arena y las de tierra, siendo las botellas con grava la que poseían menor capacidad de resistencia a la compresión.

b. La elaboración de los diseños de fundaciones y columnas para construir el prototipo.

Antes de construir el prototipo se realizó el diseño de fundaciones, que consisten una solera de fundación de $1.50 \times 0.40 \mathrm{~m}$, con acero longitudinal de $3 / 8$ " con estribos a cada $0.15 \mathrm{~m}$ de I/4" y refuerzo vertical 2 varillas de $1 / 2^{\prime \prime}$ a sus extremos, y la dosificación del concreto se utilizó $1: 2: 2$.

Para realizar las columnas se utilizaron bloques de concreto con las medidas de $15 \times 20 \times 40$ rellenos de concreto y con un acero vertical de I/2".

La solera intermedia y de coronamiento se hizo con acero longitudinal de 3/8", con estribos a cada $0.15 \mathrm{~m}$ de I/4" y refuerzo vertical de 2 varillas de $\mathrm{I} / 2^{\text {" }}$ a sus extremos y la dosificación del concreto se utilizó I:2:2. Y para la dosificación del material para pegar las botellas, se realizó con material selecto y cemento cuya dosificación fue de 2:1/4 carretilladas de material selecto y un cuarto de una bolsa de cemento.

c. La construcción de los prototipos de un muro de mampostería confinada con botellas de PET. 
Se procedió a conseguir los materiales que se utilizarían: acero, cemento, bloques, arena, grava, material selecto y cemento. Se realizó la excavación para la solera de fundación, se niveló, se realizó el armado de la solera de fundación y seguidamente se rellenó con el concreto dosificación 1:2:2. Se dejó a cada extremo de la solera 2 varillas de acero vertical de $1 / 2 "$, en las cuales se colocaron los bloques, haciendo la función de columnas. Se comenzó a colocar las botellas en filas, amarradas entre ellas con nylon en el punto central y frontal de las botellas, uniéndolas con la mezcla de lodocreto, para la cual se utilizó una dosificación de dos carretilladas de material selecto y un cuarto de una bolsa de cemento.

d. La evaluación del comportamiento del muro aplicando esfuerzos de tensión y compresión.

Para evaluar el comportamiento del muro se aplicaron esfuerzos de compresión a una muestra de botellas con diferentes materiales. Las que fueron rellenas de tierra llegaron a soportar $80.72 \mathrm{~kg} / \mathrm{cm} 2$; las rellenas de arena, $111.56 \mathrm{~kg} / \mathrm{cm} 2$, y las rellenas con grava, 8.74 $\mathrm{kg} / \mathrm{cm} 2$, dando como resultado que las mejores resistencias a la compresión fueron las de las botellas rellenas con arena y tierra. Los esfuerzos de compresión se dan bajo estándares de calidad, con los aceros bajo norma American Society for Testing and Materials "ASTM". Se realizó una visita para la evaluación de este sistema constructivo por parte de la Fundación Hábitat para la Humanidad El Salvador.

Por tanto, se realizó un diseño que no afecte al medio ambiente, sino que colabore con la disminución de contaminantes que dañan los ecosistemas y la vida. A raíz de esto se seleccionó para este estudio la filosofía de diseño de Arquitectura Verde, la cual tiene un enfoque de construcción también conocido como diseño sostenible. La arquitectura verde es simplemente un método de diseño que minimiza el impacto de la construcción sobre el medio ambiente (Taracena, 2010). En El Salvador son pocas las empresas constructoras que utilizan este tipo de diseños en sus proyectos. Falta cambiar la visión de empresarios, constructores y sociedad salvadoreña, para que se pueda realizar un cambio orientado a lo ecológico en las construcciones urbanas, respetando el ambiente y buscando la manera de que se reduzca el impacto negativo.

Es necesario hacer conciencia del daño que sufre el medio ambiente, y si no se cambia la forma de pensar en la planificación de las construcciones, se lleva un proceso de autodestrucción que afecta a plantas, animales, al ser humano y al planeta entero.

Uno de los principales problemas que posee El Salvador es el déficit habitacional que afecta a 8 salvadoreños de cada 10 (INCAE, 2016). Es necesario como sociedad, saber qué hacer 
con esas familias, ya que según el (PNUD) el 35.2\% forman parte del porcentaje de Pobreza Multidimensional.

Es necesario encontrar soluciones a esta problemática, y así mejorar la calidad de vida de muchas familias. Otra problemática que se encuentra en el país, así como a nivel mundial, es la contaminación de plásticos, que a través de la creciente demanda de productos envasados se ha producido un índice de contaminación de plásticos nunca visto, afectando los ecosistemas terrestres y acuáticos. En menos de 50 años se ha plastificado al planeta. Se estima una entrada anual al mar de 6,4 millones de toneladas de basura, unos 200 kilos cada segundo (Programa de las Naciones Unidas para el Ambiente 2009) citado por (Jaén \& González, 2019).

El Salvador no es la excepción. Un estudio realizado por (Ocean Clean up), -una fundación que desarrolla tecnología para extraer residuos plásticos y evitar que sigan entrando en las aguas del océano-, realizó un estudio en el cual enlista los 1000 ríos más contaminantes de plásticos a nivel mundial, y menciona entren ellos a dos ríos del país, el Río Paz y el Río Lempa. Anualmente el Río Lempa descarga al Océano Pacifico la cantidad de 219,000 kg. de contaminantes, mientras que el Río Paz descarga 169,000 kg. El Río Grande, si bien no está en ese listado, descarga en el mar 47,900 kg. de contaminantes. Son datos a tomar muy en cuenta para realizar políticas ambientales y de esta manera tratar de frenar la contaminación de los ríos y del Océano Pacífico.

Este estudio se realizó como como una propuesta para ayudar a contrarrestar un poco estas problemáticas. Para esto, se realizó un proceso de comparación con sistemas constructivos, y analizando diferentes viviendas que se han construidos en diferentes latitudes del planeta, todas ellas relacionadas con la temática de reciclaje de botellas PET. Entre las que se pueden mencionar construcciones de Bolivia, Colombia, México, Honduras, Serbia y muchos lugares más. Éstos fueron tomados en cuenta por el sistema constructivo similar al que se utilizó en esta investigación, pues es un sistema de marcos armados, o mampostería confinada, similar al utilizado en las paredes de ladrillo de obra. La diferencia estriba en que, en lugar de ladrillos, se utiliza las botellas PET pegadas con una mezcla llamada lodocreto, que es la unión de material selecto con cemento, si bien también se puede utilizar el mortero, una combinación de arena y cemento.

Se ha comprobado que este tipo de viviendas son viables para implementarse en El Salvador, pues se cuenta con los materiales necesarios para su desarrollo. Con respecto a los implementos ambientales, como es el caso de los sismos, es necesario realizar un estudio adecuado con respecto al diseño de columnas, nervios y vigas, para que la edificación sea 
resistente a este tipo de condiciones.

En los países que han tomado la iniciativa de construcciones sostenibles, han roto paradigmas, convenciendo a las autoridades y usuarios de estas viviendas a cambiar los materiales tradicionales por un nuevo sistema innovador y amigable con el medio ambiente, comprobando la eficiencia y beneficios que puede tener este tipo de construcciones en lo económico, en la seguridad, en la salud y con el medio ambiente. En El Salvador es necesario romper con muchos paradigmas para poder echar a andar este tipo de proyectos. Beneficios como resistencia, durabilidad, abundancia del material de construcción y la producción de un microclima interior fresco por el día y cálido por las noches, son cualidades que hacen que este tipo de edificaciones se puedan utilizar en El Salvador.

La resistencia individual de un ladrillo de barro sólido y hueco oscila de 87.5 y $175 \mathrm{~kg} / \mathrm{cm} 2$, y el de un bloque de concreto entre 77 y 105 kg/cm2, según la Norma Técnica Para Diseño Estructural De Mampostería (Asamblea legislativa de El Salvador, 2002). La botella con relleno de tierra alcanzó una resistencia entre 80 y $85 \mathrm{Kg} / \mathrm{cm} 2$, y una resistencia de I I I kg/ $\mathrm{cm} 2$, utilizando arena de relleno, convirtiéndose en un excelente material de construcción, por su resistencia y su durabilidad.

Con estos parámetros, se observa que la resistencia obtenida en la investigación se encuentra entre los rangos que requiere la Norma Técnica Para Diseño Estructural De Mampostería de El Salvador, convirtiéndolo en una excelente opción para construir de una forma amigable con el medio ambiente, y reduciendo los costos de construcción de viviendas, además de los beneficios similares a las casas construidas con adobe, siendo éstas más resistente a la humedad.

Otro factor que hay que tomar en cuenta es que para la construcción de los bloques de concreto hay que utilizar ciertas cantidades de cemento, y para fabricar cemento se necesita calentar arcilla y caliza en horno giratorio a una temperatura aproximada de $1450^{\circ} \mathrm{C}$, el cual produce 3,000 kilogramos de dióxido de carbono (CO2) por tonelada. Además, el proceso de calentamiento provoca una reacción química por la transformación del carbono, de calcio en óxido de calcio, que desprende unos 2,200 kilogramos de CO2 al medio ambiente haciendo un total de 5,200kg de CO2 (Smith, 2018). Estos procesos no serían necesarios en el caso de la propuesta de esta investigación.

Con esto se aprecia que, utilizando materiales reciclados se puede construir y a su vez reducir la cantidad de basura, y al no utilizar grandes cantidades bloques de concreto, se evita la contaminación por CO2 que se produce con la fabricación del cemento, el cual conlleva a los cambios bioclimáticos que afectan al planeta entero. 
Con la utilización de esta nueva tecnología de construcción de viviendas, se busca favorecer a las familias más vulnerables de la sociedad por falta de una vivienda digna, reducir los costos de construcción en la edificación de viviendas de tipo social y la contaminación plástica que afecta quebradas, ríos, mares y superficie terrestre, ofreciendo un excelente material de construcción por su durabilidad y abundancia.

Según la información recabada, se recomienda para su construcción dejar un máximo de espacio de $3 \mathrm{~m}$ entre columnas, para mantener la estabilidad de la pared y a su vez que funcionen como apoyo para la estructura de techo. Las columnas serían las que soporten el peso y de esta manera las paredes soportarán solamente su propio peso, evitando un esfuerzo de compresión y tensión extra. Para que la construcción no sea muy costosa, se pueden utilizar las columnas principales a cada $6 \mathrm{~m}$, dejando entre las dos columnas un tensor que haga las veces de columnas, pero sin soportar mucho peso.

Los mayores retos que tienen estas iniciativas de construcciones en El Salvador, es que se posee un estilo tradicional de construcción, avaladas por la Ley de Urbanismo y Construcción, y por ahora no existen edificaciones de botellas recicladas, no hay registro de construcciones con base técnica. Además, los usuarios de estas viviendas podrían no sentirse seguros en un inicio por este tipo de construcciones, lo cual haría que opten por la utilización de una vivienda tradicional de bloques o ladrillos de barro cocido.

Hay que hacer cambios de pensamientos de que estas edificaciones sustentables son de la misma calidad que las tradicionales, que los constructores del país miren como una alternativa para sus proyectos haciendo alianzas estratégicas con plantas recicladoras de plástico, embotelladoras y con pequeños proveedores para la recolección de la principal materia prima, que es la botella de PET.

Todo esto es necesario, para poder mejorar las condiciones de vida de muchos salvadoreños que no poseen vivienda y dar, así, una esperanza de mejor vida a las generaciones venideras. Por lo tanto, los resultados y/o hallazgos de la investigación permiten analizar e interpretar las siguientes perspectivas de análisis.

\section{- Apostarle a desarrollar estrategias y modelos de construcción ecológicos:}

El Salvador, se posee una Ley de Urbanismo y Construcción aprobada en 1991, que no contempla los nuevos métodos de construcción existentes en el mundo. Se hace necesario actualizar la ley y realizar un manual que explique estas nuevas tecnologías de la construcción, siendo necesario incluir las construcciones sostenibles con materiales 
reciclados para estandarizar las proporciones de los materiales y la calidad de la construcción.

\section{- Incorporar en los conceptos de construcción a base de material reciclado PET, las} bases de la economía circular:

Se hace necesario dar a comprender al gobierno, a la población y a las empresas privadas sobre la necesidad del reciclaje, en especial de las botellas de PET, pues es un material que tarda muchos años en degradarse. Al ocuparse como principal fuente de construcción de viviendas reutilizamos materiales ya existentes, sin tener la necesidad de hacer nuevos elementos de construcción desde cero.

\section{- Desarrollar estrategias para el diseño de viviendas de bajo costo y ecológicas:}

Al ser un material $100 \%$ reciclado no genera un costo directo para los constructores ni para los usuarios; se hace necesario, entonces, realizar alianzas entre las comunidades, el gobierno, las Organizaciones no gubernamentales, las escuelas y colegios, para la recolección de las botellas, para recaudar el mayor número y reducir la contaminación del medio ambiente.

- Asociar el abordaje de la arquitectura verde y arquitectura sostenible en la construcción de viviendas a base de productos PET:

La arquitectura verde y la arquitectura sustentable invitan a los constructores a buscar nuevos materiales y nuevas formas de diseñar que vayan de la mano con el medio ambiente, que sean seguros para los usuarios y que representen un nuevo estilo de vida para la población.

\section{- Propiciar en los conceptos de diseño de vivienda a base de material reciclado PET} los objetivos de la Agenda 2030:

Al utilizar las botellas de PET como un nuevo material de construcción se busca beneficiar a la población de bajos recursos económicos. Se puede capacitar este sector de la población para que se puedan crear comunidades sostenibles cumpliendo de esta manera el objetivo número Once de los Objetivos de Desarrollo Sostenible, convirtiéndose en comunidades de desarrollo local, siendo capaces de planificar, gestionar y elaborar lo necesario para sacar adelante los asentamientos urbanos y rurales.

Para construir este tipo de edificaciones se hace necesario realizar campañas de limpieza y recolección, cuyos principales puntos de recolección pueden ser quebradas y ríos. Con esto 
se busca reducir los niveles de plásticos que afectan los ecosistemas marinos, puesto que muchas de las botellas, al no ser recicladas ni darles un tratamiento adecuado, finalizan en el océano, afectando las diferentes especies que viven en los ecosistemas acuáticos. Se cumpliría así, cumpliendo de esta manera el objetivo número Catorce de los Objetivos del Desarrollo Sostenible orientado a la vida submarina.

De igual manera con las campañas de limpieza y recolección que se llevarían a cabo, se ayudaría a la disminución de los contaminantes en los ecosistemas terrestres, pues se evitaría que estas botellas fueran quemadas o enterradas, dando cumplimiento al objetivo número Quince de los Objetivos del Desarrollo Sostenible.

\section{Conclusiones}

En la realidad actual del planeta las construcciones sustentables ayudan al medio ambiente, ante la creciente alza de materiales plásticos que se ha generado a partir de 1950, 'plastificando' el mundo en menos de medio siglo. Las grandes industrias generan toneladas de desechos plásticos diarios, que los consumidores usan y desechan, a los cuales no se les da un tratamiento especial para reciclaje. Solamente se recicla del 10 al $20 \%$, mientras el $80 \%$ es quemados, enterrado y arrojado diariamente a los océanos, afectando de esta manera la vida submarina. Estos materiales tardan aproximadamente 700 años en degradarse. Al realizar este tipo de construcciones se ayudará a muchos salvadoreños de escasos recursos para construir viviendas de buena calidad y económicas, dando fuentes de empleo a constructores locales, recicladores, microempresas y empresas recicladores de plástico del país y dándole un nuevo uso a las botellas convirtiéndolas en ladrillos ecológicos, material que por sus características individuales, como durabilidad y resistencia, las hace excelente material a tomar en cuenta para futuras edificaciones en El Salvador.

Es de tomar en cuenta que el plástico es un material reciclable y reutilizable, que posee muchas características que lo hacen un buen material de construcción, pues es impermeable, duradero, es abundante y fácil de recolectar, es resistente y al combinarlo con tierra o arena lo hace un buen sustituto de los ladrillos de barro cocido o de los bloques de concreto. Se eliminan, así, contaminantes de $\mathrm{CO} 2$ a la hora de su fabricación. Es una buena opción para el ahorro en una construcción, ya que se reducen directamente los costos de materiales como bloques, arena, y refuerzo vertical que se utiliza en el sistema de construcción de bloques, siendo sustituido por un sistema de marco armado y mampostería confinada, utilizando para pegar las botellas de lodocreto mencionado. 
Por ser las botellas rellenas de tierra, poseen las mismas características que las construcciones de adobe, climatizando el interior de la casa a una temperatura fresca durante el día y por agradable las noches, reduciendo la necesidad de utilizar mecanismos para climatizar el hogar, como es el caso de aparatos de aire acondicionado, reduciendo de esta manera la producción de $\mathrm{CO} 2$ que se produce al utilizarlo.

\section{Recomendaciones}

Por ser un sistema de construcción nuevo en el país, en necesario realizar diferentes pruebas de resistencia y seguridad estructural y a su vez un manual técnico para construcciones sostenibles, que tendría que ser evaluado por un equipo multidisciplinario de ingenieros y arquitectos, y ser aprobado por las autoridades correspondientes.

Aunque existen antecedentes de viviendas de este tipo elaboradas con botellas llenas con agua, no se recomienda puesto que existe la posibilidad de fuga de agua, $y$ esta humedad puede afectar la estructura de la pared.

Los nervios y/o columnas de refuerzo deben tener un máximo de separación de $3 \mathrm{~m}$, cuando es una pared lineal, si no se hace de esta manera puede afectar la estabilidad de la pared.

La dosificación que se utilizó para el prototipo fue de 2 carretillas de material selecto y $1 / 4$ de cemento, esta dosificación cambiaría si en lugar de la tierra blanca se utiliza área y cemento para hacer mortero.

\section{Bibliografía}

Arquitectos sin fronteras. (8 de mayo de 201I). Recuperado el 2019, de http://asfes.org/galicia/ RecursosEducativos/Unidades_Didacticas/Construimos_Reciclamos/Manual_construccion_botellas.pdf

Ander, E. (20II). Aprender a investigar : nociones básicas para la investigación social. - la ed. Argentina: Editorial Brujas. Recuperado el 14 de agosto de 2019, de http://abacoenred.com/wp-content/uploads/2017/05/Aprendera-investigar-nociones-basicas-Ander-Egg-Ezequiel-20I I.pdf.pdf

Asamblea legislativa. (2002). Norma Tecnica Para Diseño Estructural De Mamposteria. San Salvador. Recuperado el 26 de septiembre de 2019

Asamblea legislativa de El Salvador. (2002). Norma Tecnica Para Diseño Estructural De Mamposteria. San Salvador. Recuperado el 26 de septiembre de 2019

Hernández Sampieri , R., Fernandez, C., \& Baptista, P. (2000). Acervos Digitales Universidad de las Américas Puebla. Recuperado el 15 de julio de 2019, de http://catarina.udlap.mx/u_dl_a/tales/documentos/lco/ mendez_r_ji/capitulo4.pdf

INCAE. (2016). Estado de la vivienda en Centro America. Recuperado el 5 de septiembre de 20I9, de http:// x.incae.edu/ES/clacds/publicaciones/pdf/Estado_de_la_Vivienda_en_CA.pdf

Jaén, E., \& González, B. (2019). Los futuros maestros ante el problema de la contaminación de los mares por 
plásticos y el consumo. Eureka sobre Enseñanza y Divulgación de las Ciencias, I50I-I50I. Recuperado el II de septiembre de 2019, de https://reuredc.uca.es/index.php/eureka/article/download/4I54/4 I09

Nuñez, A. (2008). Obtenido de http://www.csj.gob.sv/ambiente/DOCUMENTOS/Reciclaje_Plastico.pdf

Ocean Clean up. (s.f.). the ocean clean up. Recuperado el 29 de octubre de 2019, de River plastic emissions to the world's oceans: https://theoceancleanup.com/sources/

PNUD. (20I5). Medición multidimensional de la pobreza. San Salvador. Recuperado el 5 de septiembre de 2019 , de https://www.undp.org/content/dam/el_salvador/docs/povred/

Medici\%c3\%b3n\%20Multidimensional\%20de\%20la\%20Pobreza\%20El\%20Salvador.pdf

Smith, P. F. (2018). La Arquitectura en un clima de cambio "Una guía para el diseño sostenible". Barcelona: Reverté. Recuperado el 27 de septiembre de 2019

Taracena, V. (2010). Arquitectura Verde. Cultura de Guatemala, 55. Obtenido de http://216.230.140.12/PortalURL/ Archivos/I 72/archivos/RCG\%2002-2010\%20reflexiones\%20y\%20aporte.pdf\#page=56 